\title{
Effect of Layers Thickness and Temperature on Electronic Transport of Nanostructures Infrared Detectors
}

\author{
Nassima Benchtaber, Abdelhakim Nafidi, Samir Melkoud, Meriem Benaadad, Driss Barkissy \\ Laboratory of Condensed Matter Physics and Nanomaterials for Renewable Energy \\ Department of Physics Faculty of Sciences Ibn Zohr University \\ Agadir, Morocco
}

\begin{abstract}
We report here the effect of layers thickness and temperature on electronic transport of nanostructure by calculation of band structure of two superlattices SL 1 $\operatorname{InAs}\left(d_{1}\right) / \operatorname{Gasb}\left(d_{2}\right)$ of type II and SL2 $\mathrm{HgTe} / \mathrm{CdTe}$ of type III for infrared detection application. These studies were done using the envelope function formalism. We calculated the energy of carriers as a function of layers thickness, the ration $d_{1} / d_{2}$ and the temperature. The calculated density of states and Fermi level energy shows that temperature generated transitions from quasi bidimensional (Q2D) to three dimensional (3D) in the two SL. The later occurred near $20 \mathrm{~K}$ in the $p$ type SL1 and near 84 $K$ in SL2 with $p$ type to $n$ type conductivity transition. We found that these SL are mid infrared and terahertz detectors. The electronic transport parameters calculated here are necessary for the design of infrared photo-detectors.
\end{abstract}

Keywords-Superlattices nanostructures; mid infrared detector; density of state; semiconductors; band structures.

\section{INTRODUCTION}

Infrared detection can be used in a wide range of areas, including remote sensing, astronomy, medicine, surveillance and defense ... Many of these applications, require high sensitivity on a specific band of wavelengths, use infrared systems based on semiconductors [1].

The requirements of the next generation of infrared systems, which are mainly high performance, large bay sizes and high temperature operation, have led to intensive research in industry and academia [2]. This, coupled with the continued development of new growth technologies, has encouraged researchers to study alternative materials suitable for these infrared systems [3].

The infrared detectors based materials are III-V and II-VI semiconductors, The objective of this paper is to study the two type of theses materials superlattice type II $\left(\mathrm{SL}_{1}\right)$ wich was Proposed by Mailhiot and Smith [4] in 1987, InAs / GaSb is a stress layer system with Type II band alignment, in which the InAs conduction band is located under the $\mathrm{GaSb}$ valence band. As a result, the super-network may have a smaller band gap than any of its components [5]. Electrons and holes tend to reside in different places; electron layers in InAs, and holes in $\mathrm{GaSb}$. And the superlattice type III $\left(\mathrm{SL}_{2}\right)$ The peculiarity of this type of superlattice is related to the inversion of light particle bands in HgTe compared to that of CdTe [6]. The energy difference of the peaks of the heavy-hole bands, estimated to be zero [7] but found to be as low as $40 \mathrm{meV}$ by magneto-optical measurements [8].
In order to determine the effect of layers thickness and temperature on electronic band structure of these superlattices we have calculated the band structure, band gap energy, the cutoff wavelength and the density of state and we found that $\mathrm{SL}_{1}$ and $\mathrm{SL}_{2}$ are mid infrared detector materials.

\section{THEORY OF BAND STRUCTURE}

The dispersion relation for electrons, light and heavy holes bands is written as $[9,10]$ :

$$
\begin{aligned}
& \cos =\left[\mathrm{k}_{\mathrm{z}}\left(\mathrm{d}_{1}+\mathrm{d}_{2}\right)\right]=\cos \left(\mathrm{k}_{1} \mathrm{~d}_{1}\right) \cos \left(\mathrm{k}_{2} \mathrm{~d}_{2}\right)-\frac{1}{2}\left[\left(\xi+\frac{1}{\xi}\right)+\right. \\
& \left.\frac{\mathrm{k}_{\mathrm{p}}{ }^{2}}{4 \mathrm{k}_{1} \mathrm{k}_{2}}\left(\mathrm{r}+\frac{1}{\mathrm{r}}-2\right)\right] \sin \left(\mathrm{k}_{1} \mathrm{~d}_{1}\right) \sin \left(\mathrm{k}_{2} \mathrm{~d}_{2}\right)
\end{aligned}
$$

With $\mathrm{k}_{\mathrm{z}}$ and $\mathrm{k}_{\mathrm{p}}\left(\mathrm{k}_{\mathrm{x}}, \mathrm{k}_{\mathrm{y}}\right)$ the wave vector in the growth direction and in-plane of the superlattice and 1,2 refet to the layers of the SL.

The two samples studied here are $\mathrm{SL}_{1} \operatorname{InAs}\left(\mathrm{d}_{1}=21\right.$ $\AA) / \operatorname{GaSb}\left(\mathrm{d}_{2}=24 \AA\right)$ and $\mathrm{SL}_{2} \operatorname{HgTe}\left(\mathrm{d}_{1}=45 \AA\right) / \operatorname{CdTe}\left(\mathrm{d}_{2}=48\right.$ $\AA$ ) with periods $d=d_{1}+d_{2}=45 \AA$ and $93 \AA$ and the ratio $d_{1} / d_{2}=$ 0,875 and 0,9375 , respectively. So the period of $\mathrm{SL}_{2}$ is the double of that of $\mathrm{SL}_{1}$ with the same ratio $\mathrm{d}_{1} / \mathrm{d}_{2}$ near 0.9 .

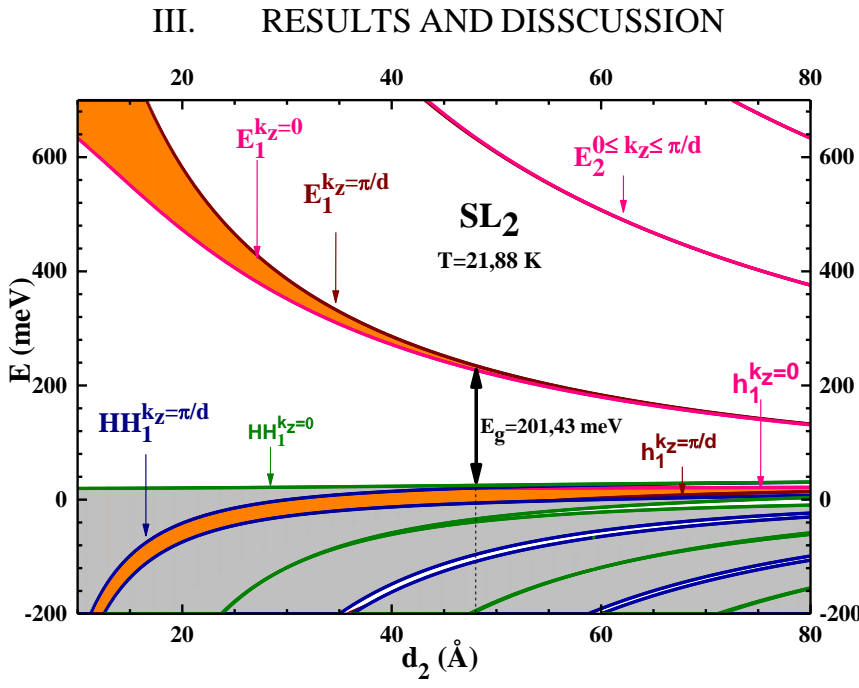

Figure 1: Calculated bands energy of electrons $\left(\mathrm{E}_{\mathrm{i}}\right)$, heavy-hole $\left(\mathrm{HH}_{\mathrm{i}}\right)$, and light-hole $\left(\mathrm{h}_{\mathrm{i}}\right)$ subbands calculated at $21.88 \mathrm{~K}$, in the first Brillouin zone as a function of the barrier thickness $\mathrm{d}_{2}$ of $(\mathrm{CdTe})$. 


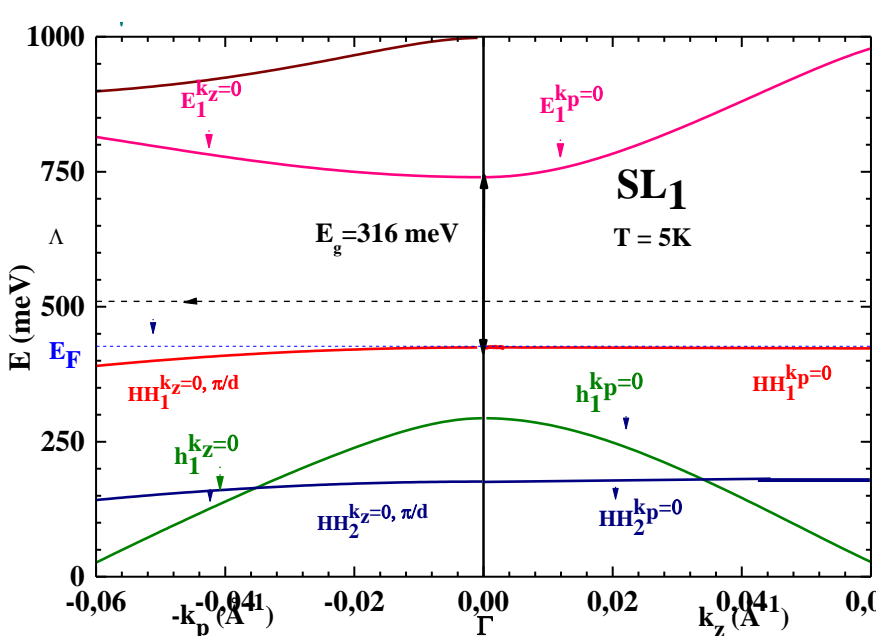

Figure 2. Band structures of the $\mathrm{SL}_{1}$ along the $\mathrm{k}_{\mathrm{z}}$ and $\mathrm{k}_{\mathrm{p}}$ directions at $5 \mathrm{~K}$

This study is done using the envelope function formalism and a various parameters like valence band offset, Kane matrix elements and effective masses of the layers.

Figure 1 show the band structure of the $\mathrm{SL}_{2}$. We plotted the energy as function of layer thickness $d_{2}$ of the barrier CdTe. We found that if $d_{2}$ increases the width of the bands and the band gap deceases. Our theoretical band gap energy is $\mathrm{E}_{\mathrm{g}}=\mathrm{E}_{1}-\mathrm{HH}_{1}=201.43 \mathrm{meV}$ at $21.88 \mathrm{~K}$.

Figure 2 shows the calculated band structure of $\mathrm{SL}_{1}$ along the wave vectors $k_{z}$ and $k_{p}$ directions at the $T=5 K$. This SL1 is semiconductor type $\mathrm{p}$ with a positive band gap energy $\mathrm{E}_{\mathrm{g}}=316$ $\mathrm{meV}$. Along $\mathrm{k}_{\mathrm{p}}$ the first conduction sub-band $\mathrm{E}_{1}$ and first light hole suband $h_{1}$ increases with $\mathrm{k}_{\mathrm{p}}$. whereas $\mathrm{HH}_{1}$ and $\mathrm{HH}_{2}$ decreases. Along $\mathrm{k}_{\mathrm{z}}$, the observed week widths of subands (7.5 $\mathrm{meV}$ for $\mathrm{E}_{1}, 6.4 \mathrm{meV}$ for $\mathrm{HH}_{1}$ and $8 \mathrm{meV}$ for $\mathrm{h}_{1}$ ) indicated a week coupling between the HgTe quantum wells. So, the parallel electronic transport governs in the plane of this superlattice.

The band gap energy $\mathrm{E}_{\mathrm{g}}$ as function of the temperature for $\mathrm{SL}_{1}$ and $\mathrm{SL}_{2}$ is shown in Figure. 3 (a). When the temperature increases the energy band gap decreases for $\mathrm{SL}_{1}$ and increases for $\mathrm{SL}_{2}$.

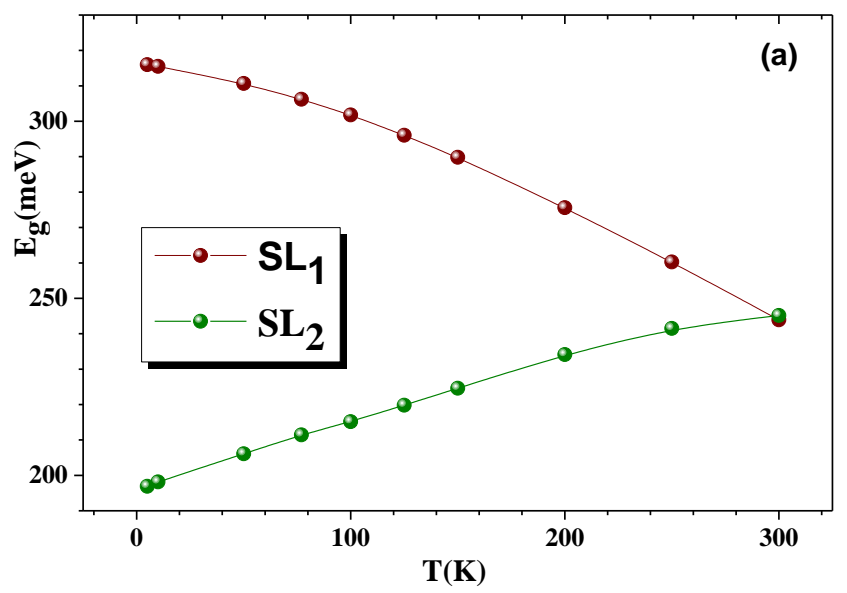

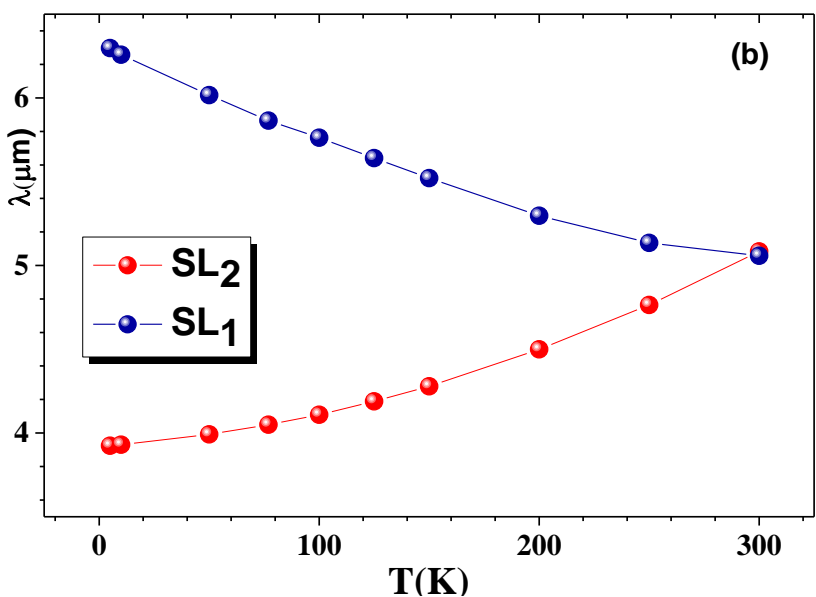

Figure 3. (a) Band gap energy of the $\mathrm{SL}_{1}$ and $\mathrm{SL}_{2}$ as function of temperature (b) the cutoff wavelength of the two samples $\mathrm{SL}_{1}$ and $\mathrm{SL}_{2}$ as function of temperature.

In figure 3 (b) we have calculated the cutoff wavelength for the $\mathrm{SL}_{1}$ and $\mathrm{SL}_{2}$, using the following formulate [11-12]:

$$
\lambda_{c}(\mathrm{~nm})=\frac{1240}{E_{g}(\mathrm{eV})}
$$

We found that when the temperature increases the cut off wavelength of $\mathrm{SL}_{1}$ decreases and that of the $\mathrm{SL}_{2}$ increases.

In order to test the effect of layer thickness on the band structure we have calculated and plotted the energy band gap as a function of layer thickness at three temperature $(5,77$ and $300 \mathrm{~K})$ for $\mathrm{SL}_{1}$ Figure 4 (a) and $(21.9,150$ and $300 \mathrm{k})$ for $\mathrm{SL}_{2}$ respectively Figure 4 (b).

We found that for $\mathrm{SL}_{1}$ at fixed temperature and if the thickness $d_{2}$ increases $E_{g}$ decreases goes to zero and became negative accusing transition conductivity from semiconductor to semi metal. When the temperature increases, at given $d_{2}$ the gap decreases and the critical thickness of the transition goes to higher $\mathrm{d}_{2 \mathrm{c}}$.

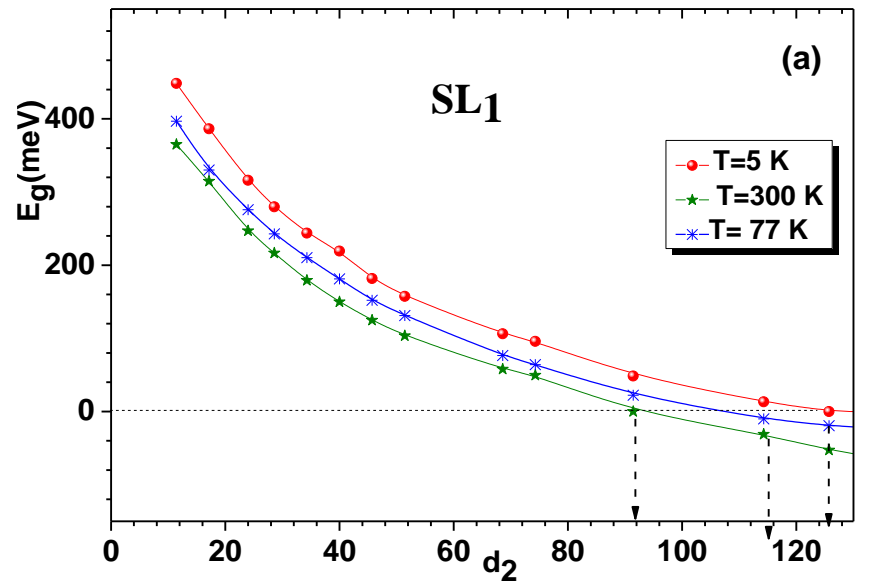




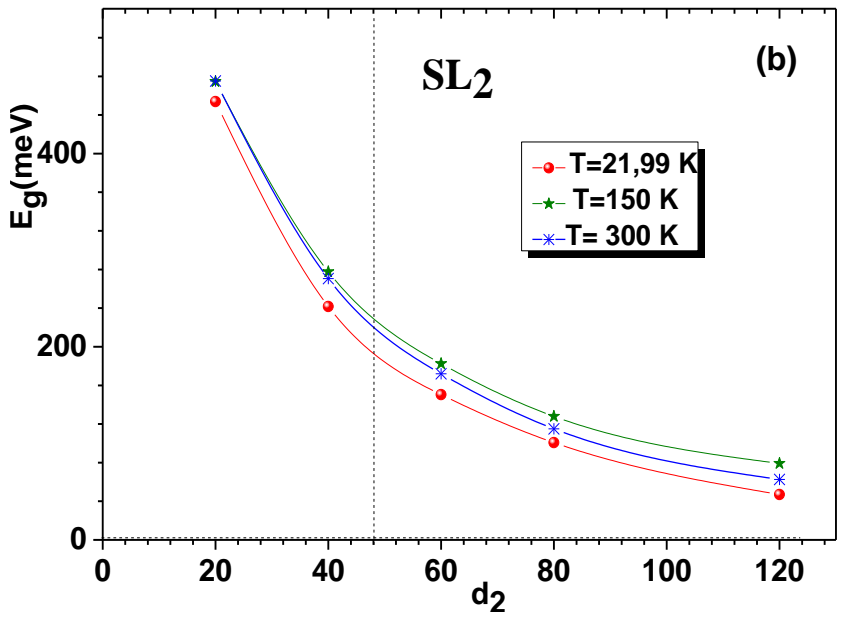

Fig.4. (a) $\mathrm{E}_{\mathrm{g}}$ as a function of $\mathrm{d}_{2}$ at three temperatures $\mathrm{SL}_{1}(\mathrm{~T}=5,77$ and $300 \mathrm{~K})$ (b) $\mathrm{E}_{\mathrm{g}}$ as a function of $\mathrm{d}_{2}$ at three temperatures $\mathrm{SL}_{2}(\mathrm{~T}=21.99,150$ and $300 \mathrm{~K})$

The $\mathrm{SL}_{2}$ is semiconductor with gap energy positive. At fixed temperature when $d_{2}$ increases the energy band gap decreases.

Our calculated band gap is $316 \mathrm{meV}$ in agreement with the measured $300 \mathrm{meV}$ for $\mathrm{SL}_{1}$ in [16]. In the $\mathrm{SL}_{2}$ the observed $E_{g}=244.1 \mathrm{meV}$ of $\mathrm{f} \mathrm{H.S}$. Jung et al. [17] is in good agreement.
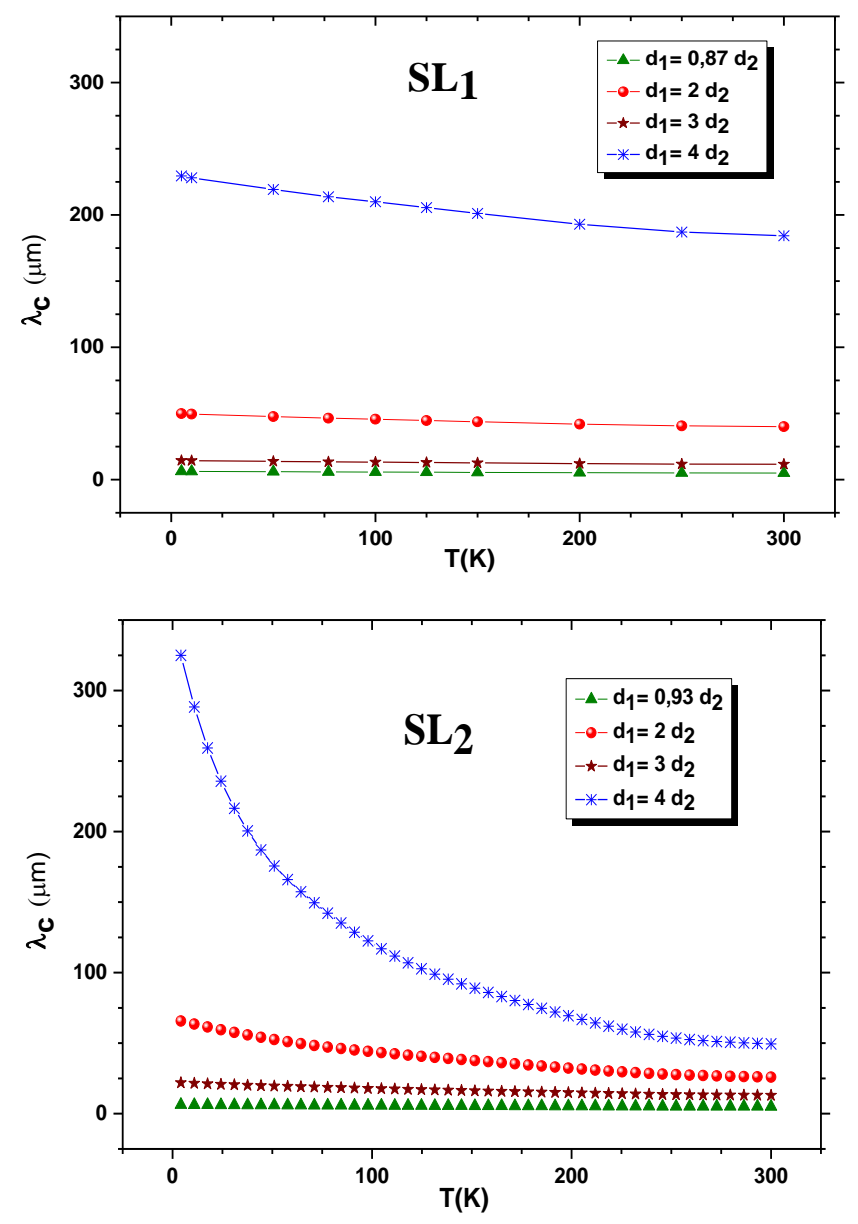

Figure 5: (a) The cut-off wavelength $\lambda_{\mathrm{c}}$ as function of the temperature for various $d_{1} / d_{2}$ in the $S L_{1}$. (b) The cut-off wavelength $\lambda_{c}$ as function of the temperature for various $d_{1} / d_{2}$ in the $S L_{2}$ with our calculated band gap $\mathrm{E}_{\mathrm{g}}(300 \mathrm{~K})=245.15 \mathrm{meV}$.

In figure 5 (a) the cut off wavelength $\lambda_{c}$ decreases when the temperature increases and for a given temperature it decreases when $d_{1} / d_{2}$ increases.

In figure $5(\mathrm{~b})$ the cut off wavelength $\lambda_{\mathrm{c}}$ decreases when the temperature increases and for a given temperature it decreases when $\mathrm{d}_{1} / \mathrm{d}_{2}$ increases. In the investigated temperature range of $4.2 \mathrm{~K}$ to $300 \mathrm{~K}, 5060 \mathrm{~nm} \leq \lambda_{\mathrm{c}} \leq 6300$ $\mathrm{nm}$, situates this sample in the mid infrared region. [13]:

The effective masse is obtained by the expression below

$$
\left(\frac{1}{\mathrm{~m}^{*}}\right)_{\mathrm{ij}}=\frac{1}{\hbar^{2}} \frac{\partial^{2} \mathrm{E}_{\mathrm{k}_{\mathrm{ij}}}}{\partial \mathrm{k}_{\mathrm{i}} \partial \mathrm{k}_{\mathrm{j}}}
$$

The second derivation of Figure 2 along $k_{p}$ allow us the determination of the effective masse at the Fermi wave vector $\mathrm{k}_{\mathrm{F}}$.

For the determination of the dimensionality of the carriers charges in the SL we calculated the superlattice $i^{\text {th }}$ mini-band, with an energy width $\Delta \mathrm{E}=\mathrm{E}_{\text {max }}^{\mathrm{i}} \mathrm{E}_{\text {min }}^{\mathrm{i}}$, the density of states (DOS) can be written as $[14,15]$ :

$$
\rho_{\text {DOS }}^{\mathrm{i}}(E)= \begin{cases}0 & \text { for } E_{\text {min }}^{\mathrm{i}}>E>E_{\text {max }}^{\mathrm{i}} \\ \frac{\mathrm{m}^{*}}{\pi^{2} \hbar^{2}} \mathrm{k}_{\mathrm{z}}(\mathrm{E}) & \text { otherwise }\end{cases}
$$

The summation of Eq.(4) gives the total density of states as:

$$
\rho_{\mathrm{DOS}}(\mathrm{E})=\sum \rho_{\mathrm{DOS}}^{\mathrm{i}}(\mathrm{E})
$$

Figure 6 shows the calculated density of states versus energy for $\mathrm{E}_{1}, \mathrm{HH}_{1}$ and $\mathrm{h}_{1}$ mini-bands at $21.9 \mathrm{~K}$ for the $\mathrm{SL}_{2}$. At $21.88 \mathrm{~K}$, the Fermi level energy is on $\mathrm{HH}_{1}$ so the conductivity is quasi-bidimensional.

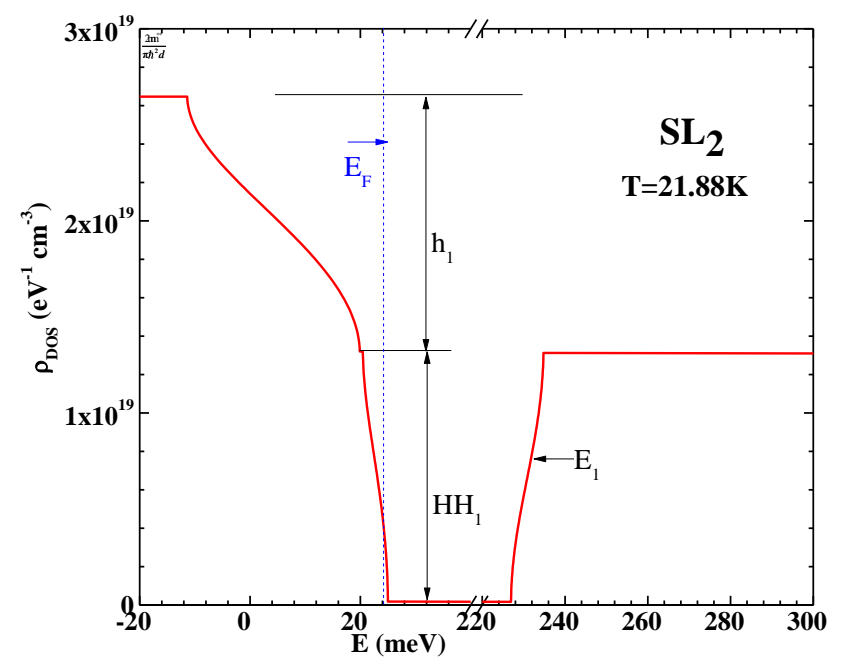

Figure 6: Density of State of the investigated superlattice $\mathrm{SL}_{2}$ at $\mathrm{T}=21.88 \mathrm{~K}$. 

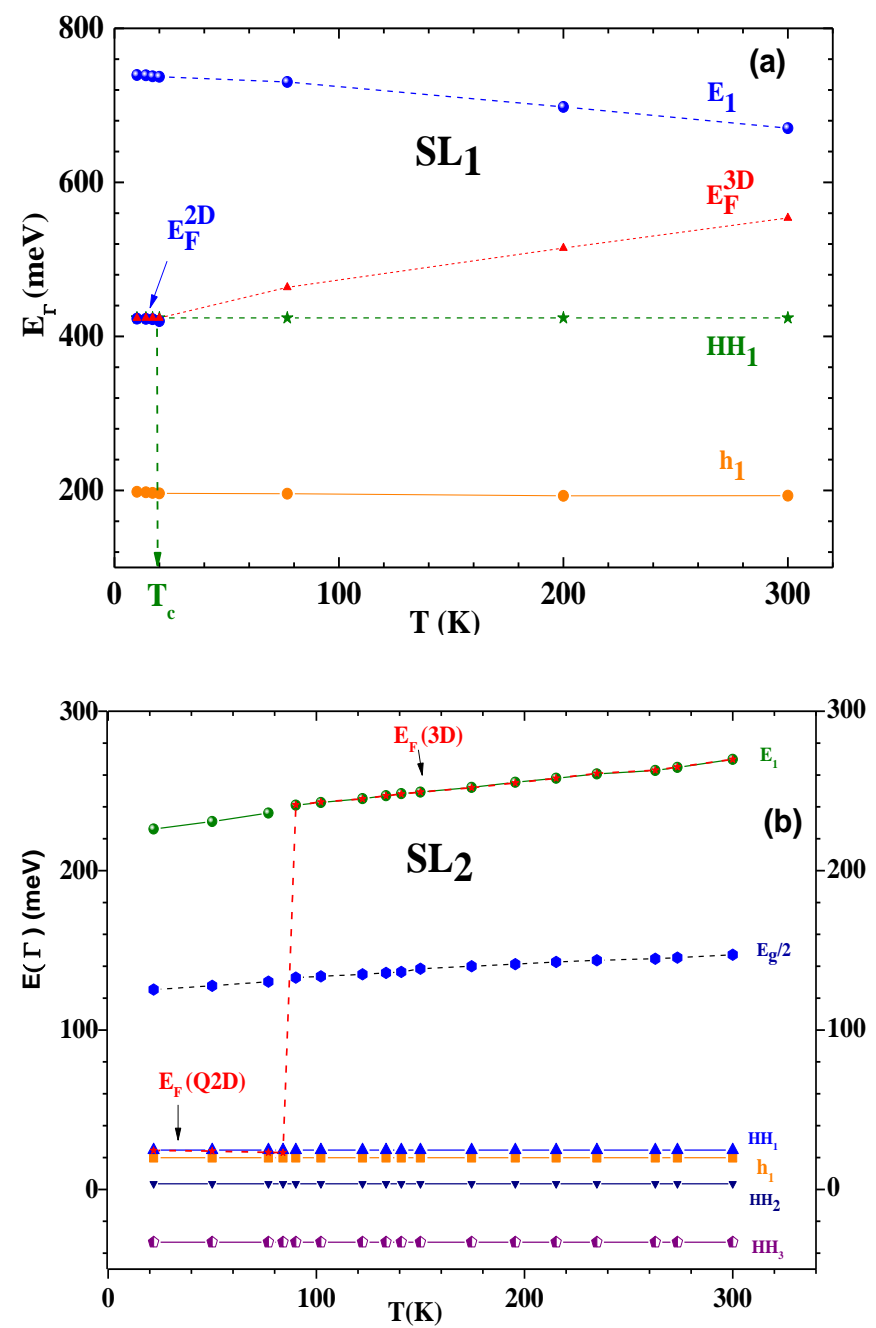

Figure 7: (a) The subbands energy at $\Gamma$ as a function of temperature and Fermi level energy transition from $2 \mathrm{D}$ to $3 \mathrm{D}$ for $\mathrm{SL}_{1}$ and (b) from $2 \mathrm{D}$ to $3 \mathrm{D}$ for $\mathrm{SL}_{2}$.

We calculated the Fermi levels using the following formulate in the $\mathrm{SL}_{1}$

$$
\begin{aligned}
& \mathrm{E}_{\mathrm{F}}=\mathrm{E}_{\mathrm{HH} 1}+\frac{\hbar^{2}\left(\mathrm{k}_{\mathrm{F}}^{\mathrm{i}}\right)^{2}}{2 \mathrm{~m}_{\mathrm{HH} 1}^{*}} \\
& \text { with } \mathrm{k}_{\mathrm{F}}^{2 \mathrm{D}}=(2 \pi \mathrm{p})^{1 / 2} \text { and } \mathrm{k}_{\mathrm{F}}^{3 \mathrm{D}}=\left(3 \pi^{2} \mathrm{p}\right)^{1 / 3}
\end{aligned}
$$

and in the $\mathrm{SL}_{2}$ :

$$
\left\{\begin{array}{l}
\mathrm{E}_{\mathrm{HH} 1}-\mathrm{E}_{\mathrm{F}}=\frac{\hbar^{2} \mathrm{k}_{\mathrm{F} 2 \mathrm{D}}^{2}}{2 \mathrm{~m}_{\mathrm{HH} 1}^{*}} \text { with } \mathrm{k}_{\mathrm{F} 2 \mathrm{D}}=(2 \pi \mathrm{p})^{1 / 2} \text { for } \mathrm{p} \text { type } \\
\mathrm{E}_{\mathrm{F}}-\mathrm{E}_{\mathrm{HH} 1}=\frac{\hbar^{2} \mathrm{k}_{\mathrm{F} 3 \mathrm{D}}^{2}}{2 \mathrm{~m}_{\mathrm{E} 1}^{*}} \text { with } \mathrm{k}_{\mathrm{F} 3 \mathrm{D}}=\left(3 \pi^{2} \mathrm{n}\right)^{1 / 3} \text { for } \mathrm{n} \text { type }
\end{array}\right.
$$

(7)

As chown in figure 7 (a) the sub-bands energy at $\Gamma$ as a function of temperature and Fermi level transition from 2D to $3 \mathrm{D}$ of the sample $\mathrm{SL}_{1}$. We found that $\mathrm{k}_{\mathrm{F} 2 \mathrm{D}}$ and $\mathrm{k}_{\mathrm{F} 3 \mathrm{D}}$ are bidimensional and tridimensional Fermi wave vector respectively. When the temperature increases, the Fermi level energy is constant (bi-dimensional gas) until $\mathrm{T}_{\mathrm{c}}=22 \mathrm{~K}$. After it increases accusing a tridimensional holes gaz.
Figure 7 (b) shows that the position of the Fermi level energy $E_{F}$, indicate $p$ type and quasi bidimentional (Q2D) holes gas at $21.9 \mathrm{~K}$. A similar Figure, at $300 \mathrm{~K}$, showed n type and 3D electrons gas in the investigated superlattice.

At $\mathrm{T}_{\text {inv }}=84 \mathrm{~K}$, the conductivity of this semiconductor sample change from p-type at low temperatures to n-type at high temperatures. Using the calculated effective mass and the concentrations of electrons from [16], the energy of Fermi level $\mathrm{E}_{\mathrm{F}}$ is constant for $\mathrm{T}<\mathrm{T}_{\text {inv }}$ and increases linearly at high temperatures. These means a transition of the carriers charges from quasi bidimensional to three-dimensional.

Our calculated gaps are in agreement with photoluminescence and transport measurements of $\mathrm{H}$. J. Haugan et al. [16] and with H.S. Jung et al. [17].

\section{CONCLUSION}

We investigate the effects of layers thickness and temperature on the electronic band structures and transport parameters in two nanostructure superlattice type II and type III. We have calculated the energy band gap; the effective masses the density of state and the Fermi level. We deduce the variation of the band gap and the cut-off wavelength as a function of the temperature and $\mathrm{d}_{1} / \mathrm{d}_{2}$. We calculated the density of states and the Fermi level as a function of temperature. We found that temperature generated transitions from quasi bidimensional holes (Q2D) to three dimensional electrons (3D) for $\mathrm{SL}_{1}$ and also $\mathrm{p}$ type to $\mathrm{n}$ type conductivity respectively for $\mathrm{SL}_{2}$.

In the investigated temperature range, the cut-off wavelength were $\left(3.92 \mu \mathrm{m}<\lambda_{c}<5.92 \mu \mathrm{m}\right)$ and $\left(5.06 \mu \mathrm{m} \leq \lambda_{\mathrm{c}} \leq\right.$ $6.30 \mu \mathrm{m})$ in the $\mathrm{SL}_{1}$ and $\mathrm{SL}_{2}$, respectively. These SL are medium infrared detectors (MWIR).

\section{REFERENCES}

[1] A.Rogalski, Infrared Detectors, Gordon and Breach Science Publishers, Amsterdam, 2000.

[2] P.R. Norton, Infrared detectors in the next millennium, Proc.SPIE 3698 (1999) 652-665.

[3] E. D. Palik, ed., Handbook of Optical Constants of Solids (Elsevier, 1998).

[4] D. L. Smith, C. Mailhiot, J. Phys. Rev. Lett. 58 (1987) 1264-1267.

[5] R. Dingle, A. C. Gossard, et W. Wiegmann, Direct Observation of Superlattice Formation in a SemiconductorHeterostructure, Phys. Rev. Lett. 34, 1327 - 1330 (1975).

[6] G. Bastard, Theoretical investigations of superlattice band structure in the envelope function approximation, Phys.Rev. B 25, $7584-$ 7597 (1982).

[7] J. T. Cheung, G. Nizawa, J. Vac. Sci. Technol. A4(4), 101 (1986).

[8] G. Bastard, Phys., Rev. B 25 (1982) 7584-7597.

[9] G. Bastard, "Teoretical investigations of superlattice band structure in the envelope-function approximation", Phys. Rev. B 25:7584, 1982.

[10] D. Barkissy, A. Nafidi, A. Boutramine, H. Charifi, A. Elanique, M Massaq, "Electronic properties of GaAs/AlAs Nanostructure superlattice", J. Low Temp. Phys. 182-185, 2016.

[11] Boutramine, A. Nafidi, D. Barkissy, M. Bellioua, A. Khalal, Correlation between electronic bands structure and magneto-transport properties of nanostructure type II superlattice for terahertz detection, Superlattices and Microstructures, Volume

127, March 2019, Pages 151-156A.

[12] D. Barkissy, A. Nafidi, A. Boutramine, E. Y. El Yakoubi, H Chaib, Investigations in electronic quantum transport of quasi two dimensional InxGa1-xAs/InP nanostructure superlattice for infrared detection, Superlattices and Microstructures, Volume 127, March 2019, Pages 54-60 
[13] S. Perkowitz, R. Sudharsanan, K. A. Harris, J. W. Cook, Jr., J. F. Schetzina, and J. N. Schulman, "Effective mass in an n-type HgTeCdTe superlattice", Journal Phys. Rev. B 36, 9290,1987.

[14] H.-S. Cho, "Density of states of quasi two one and zero dimensional superlattice", J. Vac. Sci. Technol. B Microelectron. Nanom. Struct. 7: 13-63, 1989.

[15] M. W. Prairie, R. M. Kolbas, " a general derivation of the density of states function for quantum wells and superlattices", Journal Superlattices and Microstructures, Vol. 7, No. 4, 1990.
[16] H.J. Haugan, S. Elhamri, B. Ullrich, F. Szmulowicz, G.J. Browna, W.C. Mitchel, J. Crys. Growth. (2009) 1897-1900.

[17] H.S. Jung, P. Boieriu, and C.H. Grein, "p-Type HgTe/CdTe Superlattices for Very-Long Wavelength Infrared Detectors", Journal of Electronic Materials vol. 35: no. 6, 1341-1345, 2006. 